\title{
Rancang Bangun Robot Pembersih Lantai Berbasis Arduino
}

\author{
Muhira Dzar Faraby ${ }^{1 *}$, Muhammad Akil ${ }^{2}$, Andi Fitriati ${ }^{3}$, Isminarti ${ }^{4}$ \\ Doctoral Student Electrical Engineering, ITS, Surabaya ${ }^{l}$ \\ Teknik Mekatronika, PoliteknikBosowa, Makassar ${ }^{2,3,4}$ \\ *muhira_faraby@yahoo.com
}

\begin{abstract}
This study designs an Arduino-Based Floor Cleaners Robot to help people in an efficient floor cleaning. Arduino-based floor cleaning robot consists of keeping the circuit, ie: proximity sensors, sensor drivers, motor drivers and DC motor connected to the digital ports on arduino uno. Robot will work when the proximity sensor can distinguish between black and white stripes. Simultaneously, arduino will execute the command data and continue to drive the motor so that the robot works to clean the floor. Results showed that robot cleaning the floor by following the black lines that serve as its path. The movement of the robot will transport the waste passed on the track so that the areas that have been passed robot will clean.
\end{abstract}

Keywords: robot, arduino, floor cleaners, line follower

\begin{abstract}
Abstrak
Penelitian ini merancang sebuah Robot Pembersih Lantai Berbasis Arduino yang bertujuan untuk membantu manusia dalam membersihkan lantai secara efisien. Robot pembersih lantai berbasis arduino terdiri dari beberap arangkaian, yaitu: proximity sensor, driver sensor, driver motor dan motor DC yang dihubungkan dengan ports digital pada arduino uno. Robot akan bekerja saat proximity sensor dapat membedakan garis hitam dan putih. Bersamaan dengan itu, arduino akan mengeksekusi data dan melanjutkan perintah untuk menggerakkan motor sehingga robot bekerja membersihkan lantai. Hasil pengamatan menunjukkan bahwa robot membersihkan lantai dengan mengikuti garis hitam yang dijadikan sebagai jalur kerjanya, pergerakan robot akan mengangkut sampah yang dilalui pada jalur tersebut sehingga area yang telah dilalui robot akan bersih.
\end{abstract}

Kata kunci: robot, arduino, pembersih lantai, line follower

\section{Pendahuluan}

Ruangan merupakan suatu tempat aktivitas manusia dimana hampir $90 \%$ waktu dihabiskan manusia di dalam ruangan jauh lebih lama dibandingkan di luar ruangan (udara terbuka).

Salah satu permasalahan dalam sebuah ruangan yang sering kita temui adalah kurangnya kesadaran manusia itu sendiri dalam menjaga kebersihan dalam suatu ruangan. Selain itu juga disebabkan oleh tingkat kesibukan manusia saat ini sehingga tidak sempat lagi memperhatikan kebersihan dalam ruangannya.

Permasalahan seperti diatas tentunya sangat berpengaruh terhadap kehidupan manusia. Dengan perkembangan teknologi seperti saat ini banyak orang-orang yang antusias menciptakan sebuah alat yang dapat membantu pekerjaan manusia salah satunya adalah robot.

Robot merupakan gabungan dari berbagai macam peralatan mekanik, yang dikontrol oleh peralatan elektronika dan dapat bergerak sesuai dengan fungsi tertentu. Pada saat ini, bidang elektronika sangat dibutuhkan, sebab didalam bidang ini terdapat beberapa sistem yang dapat membantu mempermudah pekerjaan manusia.

Perkembangan teknologi robotika telah mampu meningkatkan kualitas maupun kuantitas produksi berbagai pabrik. Selain itu, meningkatkan kreativitas manusia yang sangat antusias dalam merancang dan membuat robot yang tentunya mempunyai 
tujuan untuk lebih mempermudah manusia dalam melakukan pekerjaan atau aktivitasnya sehari-hari.

Oleh sebab itu, judul yang kami angkat dalam tugas akhir kami adalah "Rancang bangun robot pembersih lantai berbasis arduino". Robot ini akan membersihkan seluruh permukaan lantai dengan cara mengikuti garis. Sesuai dengan fungsinya sebagai salah satu solusi untuk mengatasi kebersihan suatu ruangan dengan memanfaatkan perkembangan teknologi saat ini terutama dalam bidang robotika.

\section{Metodologi}

Diagram blok rangkaian merupakan bagian terpenting dalam perancangan, karena dari blok diagram rangkaian inilah dapat diketahui cara kerja rangkaian keseluruhan.eseluruhan blog diagram rangkaian tersebut akan menghasilkan suatu sistem yang dapat difungsikan atau dapat bekerja sesuai dengan perancangan. Berikut blok diagram dari rangkaian sebagai berikut pada gambar 1:
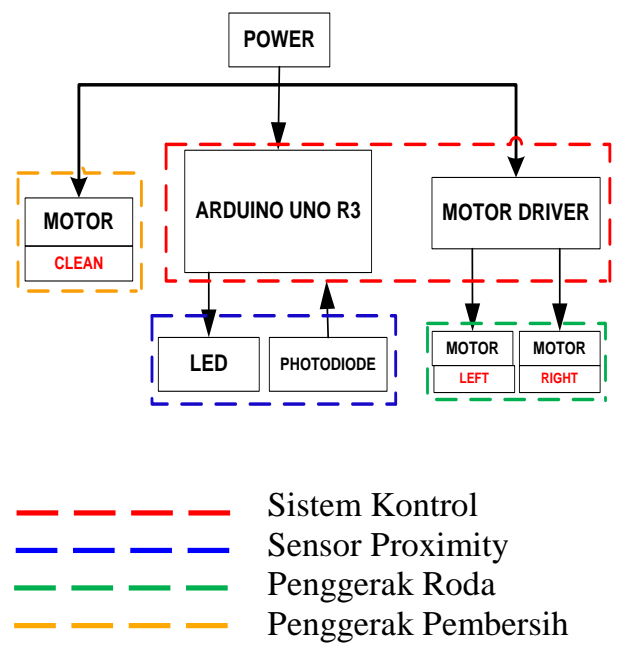

Gambar 1. Blok diagram robot pembersih lantai berbasis arduino.

Seluruh komponen robot pembersih lantai berbasis arduino seperti pada gambar 3.2 membutuhkan power sebagai sumber energi utama. Kemudian terdapat arduino uno sebagai kontrol yang memproses input dari sensor kemudian mengeluarkan output sehingga robot bisa bekerja. Selain itu, ada pula LED dan Photodioda sebagai sensor proximity untuk membaca garis yang membedakan garis hitam dan putih. Dan terdapat rangkaian motor driver sebagai rangkaian penggerak motor untuk mengontrol 2 unit motor DC. Serta terdapat pula motor DC yang langsung di kontrol oleh arduino sebagai penggerak sapu pembersih.

Berikut flowchart perencanaan rancang bangun robot pembersih lantai berbasis arduino dapat dilihat pada gambar 2:

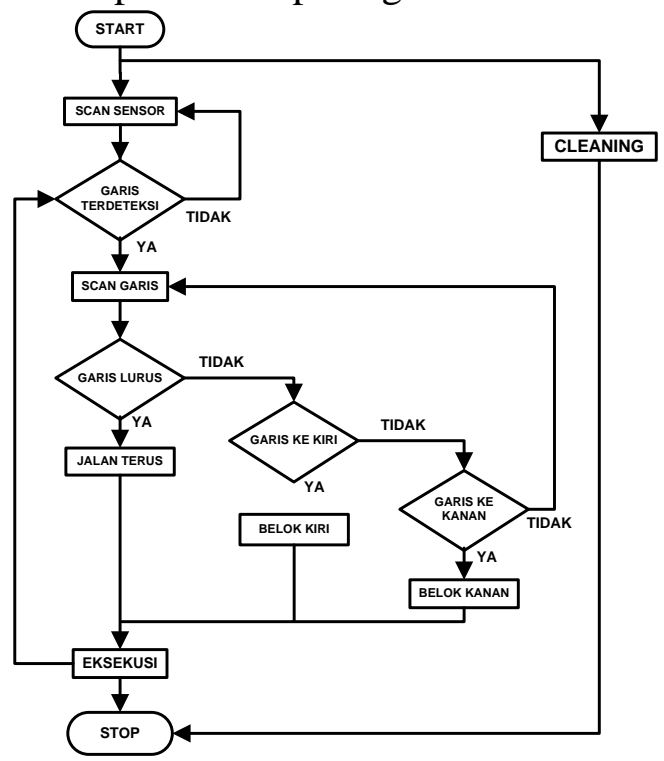

Gambar 2. Flowchart robot pembersih lantai berbasis arduino.

Pada proyek ini akan dirancang sebuah robot pembersih lantai berbasis arduino yang sesuai dengan flowchart diatas. Dimana proses kerja robot dimulai dengan menekan tombol start sehingga motor yang berfungsi sebagai pembersih akan mulai berputar. Sehubungan dengan itu, secara bersamaan pun sensor akan berfungsi dan mendeteksi garis. Ketika garis terdeteksi maka garis akan dibaca oleh sensor yaitu jika garis lurus terbaca maka itu berarti robot akan maju. Namun, ketika robot tidak mendeteksi maka sensor akan mendeteksi garis ke kiri sehingga robot akan belok ke kiri. Akan tetapi jika robot kembali tidak 
mendeteksi maka sensor akan mendeteksi garis ke kanan sehingga robot akan belok ke kanan. Namun, jika robot tidak mendeteksi garis ke kanan maka proses akan berhenti. Dan ketika robot tidak lagi mendeteksi sebuah garis maka secara otomatis motor yang menggerakkan sapu pembersih akan berhenti dan sehubungan dengan itu robot pun juga akan berhenti.

\section{Hasil Penelitian}

\subsection{Rangkaian Sensor Proximity}

Rangkaian Sensor Proximity terdiri dari komponen led yang terhubung dengan resistor akan memantulkan cahaya yang kemudian komponen photodioda yang terhubung dengan resistor akan menerima pantulan. Jika permukaan lantai berwarna putih maka photodioda akan menerima banyak cahaya dan tegangan keluaran mendekati $0 \mathrm{~V}$. Sebaliknya jika permukaan lantai berwarna hitam maka photodioda sedikit menerima cahaya sehingga tegangan keluaran sama dengan Vcc yaitu $5 \mathrm{~V}$. Gambar 3 merupkan rangkaian sensor proximity.

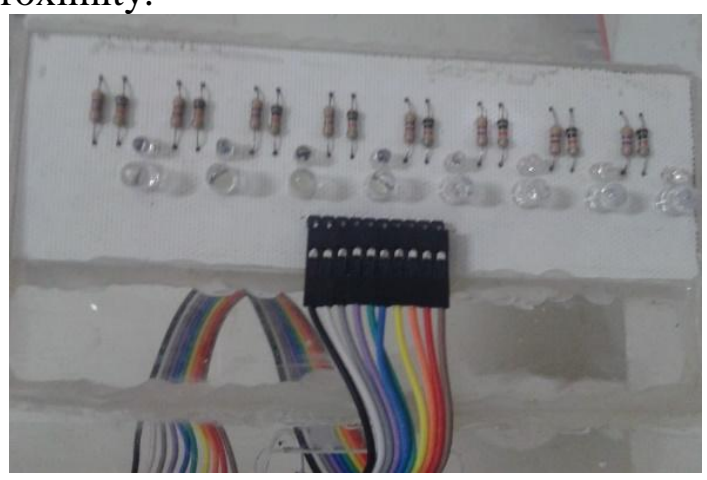

Gambar 3. Sensor Proximity.

Pengujian sensor proximity dapat dilihat pada Tabel 1 dibawah ini:
Tabel 1. Pengujian Kepekaan Sensor Cahaya Pada

\begin{tabular}{|c|c|c|c|}
\hline \multicolumn{4}{|c|}{ Permukaan Putih } \\
\hline SENSOR & $\begin{array}{c}\text { JARAK } \\
\text { DARI } \\
\text { PERMUKA } \\
\text { AN } \\
\text { LANTAI }\end{array}$ & $\begin{array}{l}\text { TEGANGAN } \\
\text { OUTPUT } \\
\text { (PERMUKA } \\
\text { AN PUTIH) }\end{array}$ & $\begin{array}{l}\text { TEGANGAN } \\
\text { OUTPUT } \\
\text { (PERMUKAA } \\
\text { N HITAM) }\end{array}$ \\
\hline \multirow[t]{6}{*}{ S1 } & $0,5 \mathrm{~cm}$ & $0,1945 \mathrm{~V}$ & $2,781 \mathrm{~V}$ \\
\hline & $1 \mathrm{~cm}$ & $0,1981 \mathrm{~V}$ & $2,825 \mathrm{~V}$ \\
\hline & $1,5 \mathrm{~cm}$ & $0,2124 \mathrm{~V}$ & $2,936 \mathrm{~V}$ \\
\hline & $2 \mathrm{~cm}$ & $0,2195 \mathrm{~V}$ & $2,966 \mathrm{~V}$ \\
\hline & $2,5 \mathrm{~cm}$ & $0,2199 \mathrm{~V}$ & $3,009 \mathrm{~V}$ \\
\hline & $3 \mathrm{~cm}$ & $0,2245 \mathrm{~V}$ & $3,067 \mathrm{~V}$ \\
\hline \multirow[t]{6}{*}{ S2 } & $0,5 \mathrm{~cm}$ & $0,2042 \mathrm{~V}$ & $3,533 \mathrm{~V}$ \\
\hline & $1 \mathrm{~cm}$ & $0,207 \mathrm{~V}$ & $3,529 \mathrm{~V}$ \\
\hline & $1,5 \mathrm{~cm}$ & $0,2154 \mathrm{~V}$ & $3,582 \mathrm{~V}$ \\
\hline & $2 \mathrm{~cm}$ & $0,2234 \mathrm{~V}$ & $3,61 \mathrm{~V}$ \\
\hline & $2,5 \mathrm{~cm}$ & $0,2268 \mathrm{~V}$ & $3,64 \mathrm{~V}$ \\
\hline & $3 \mathrm{~cm}$ & $0,2283 \mathrm{~V}$ & $3,71 \mathrm{~V}$ \\
\hline \multirow[t]{6}{*}{ S3 } & $0,5 \mathrm{~cm}$ & $0,1889 \mathrm{~V}$ & $2,740 \mathrm{~V}$ \\
\hline & $1 \mathrm{~cm}$ & $0,1909 \mathrm{~V}$ & $2,703 \mathrm{~V}$ \\
\hline & $1,5 \mathrm{~cm}$ & $0,1938 \mathrm{~V}$ & $2,787 \mathrm{~V}$ \\
\hline & $2 \mathrm{~cm}$ & $0,2124 \mathrm{~V}$ & $2,878 \mathrm{~V}$ \\
\hline & $2,5 \mathrm{~cm}$ & $0,213 \mathrm{~V}$ & $2,935 \mathrm{~V}$ \\
\hline & $3 \mathrm{~cm}$ & $0,2154 \mathrm{~V}$ & $3,010 \mathrm{~V}$ \\
\hline \multirow[t]{6}{*}{$\mathrm{S} 4$} & $0,5 \mathrm{~cm}$ & $0,1922 \mathrm{~V}$ & $3,284 \mathrm{~V}$ \\
\hline & $1 \mathrm{~cm}$ & $0,1923 \mathrm{~V}$ & $3,239 \mathrm{~V}$ \\
\hline & $1,5 \mathrm{~cm}$ & $0,1948 \mathrm{~V}$ & $3,274 \mathrm{~V}$ \\
\hline & $2 \mathrm{~cm}$ & $0,2008 \mathrm{~V}$ & $3,287 \mathrm{~V}$ \\
\hline & $2,5 \mathrm{~cm}$ & $0,2086 \mathrm{~V}$ & $3,338 \mathrm{~V}$ \\
\hline & $3 \mathrm{~cm}$ & $0,2136 \mathrm{~V}$ & $3,376 \mathrm{~V}$ \\
\hline \multirow[t]{6}{*}{ S5 } & $0,5 \mathrm{~cm}$ & $0,1926 \mathrm{~V}$ & $2,798 \mathrm{~V}$ \\
\hline & $1 \mathrm{~cm}$ & $0,1933 \mathrm{~V}$ & $2,825 \mathrm{~V}$ \\
\hline & $1,5 \mathrm{~cm}$ & $0,1975 \mathrm{~V}$ & $2,985 \mathrm{~V}$ \\
\hline & $2 \mathrm{~cm}$ & $0,2189 \mathrm{~V}$ & $3,257 \mathrm{~V}$ \\
\hline & $2,5 \mathrm{~cm}$ & $0,2189 \mathrm{~V}$ & $3,333 \mathrm{~V}$ \\
\hline & $3 \mathrm{~cm}$ & $0,2216 \mathrm{~V}$ & $3,390 \mathrm{~V}$ \\
\hline \multirow[t]{6}{*}{ S6 } & $0,5 \mathrm{~cm}$ & $0,1991 \mathrm{~V}$ & $3,058 \mathrm{~V}$ \\
\hline & $1 \mathrm{~cm}$ & $0,2041 \mathrm{~V}$ & $2,994 \mathrm{~V}$ \\
\hline & $1,5 \mathrm{~cm}$ & $0,2058 \mathrm{~V}$ & $3,015 \mathrm{~V}$ \\
\hline & $2 \mathrm{~cm}$ & $0,2259 \mathrm{~V}$ & $3,082 \mathrm{~V}$ \\
\hline & $2,5 \mathrm{~cm}$ & $0,2302 \mathrm{~V}$ & $3,152 \mathrm{~V}$ \\
\hline & $3 \mathrm{~cm}$ & $0,2322 \mathrm{~V}$ & $3,191 \mathrm{~V}$ \\
\hline \multirow[t]{6}{*}{ S7 } & $0,5 \mathrm{~cm}$ & $0,1941 \mathrm{~V}$ & $2,390 \mathrm{~V}$ \\
\hline & $1 \mathrm{~cm}$ & $0,1962 \mathrm{~V}$ & $2,278 \mathrm{~V}$ \\
\hline & $1,5 \mathrm{~cm}$ & $0,1963 \mathrm{~V}$ & $2,354 \mathrm{~V}$ \\
\hline & $2 \mathrm{~cm}$ & $0,202 \mathrm{~V}$ & $2,359 \mathrm{~V}$ \\
\hline & $2,5 \mathrm{~cm}$ & $0,2027 \mathrm{~V}$ & $2,424 \mathrm{~V}$ \\
\hline & $3 \mathrm{~cm}$ & $0,2033 \mathrm{~V}$ & $2,480 \mathrm{~V}$ \\
\hline \multirow[t]{6}{*}{ S8 } & $0,5 \mathrm{~cm}$ & $0,1931 \mathrm{~V}$ & $2,692 \mathrm{~V}$ \\
\hline & $1 \mathrm{~cm}$ & $0,1935 \mathrm{~V}$ & $2,627 \mathrm{~V}$ \\
\hline & $1,5 \mathrm{~cm}$ & $0,1967 \mathrm{~V}$ & $2,614 \mathrm{~V}$ \\
\hline & $2 \mathrm{~cm}$ & $0,2017 \mathrm{~V}$ & $2,709 \mathrm{~V}$ \\
\hline & $2,5 \mathrm{~cm}$ & $0,2038 \mathrm{~V}$ & $2,752 \mathrm{~V}$ \\
\hline & $3 \mathrm{~cm}$ & $0,2123 \mathrm{~V}$ & $2,923 \mathrm{~V}$ \\
\hline
\end{tabular}


Dari hasil tabel tersebut diperoleh hasil pengukuran tegangan keluaran berdasarkan jarak sensor dari permukaan lantai bahwa semakin jauh jarak sensor dari permukaan lantai maka semakin besar pula tegangan keluaran yang diperoleh. Selain itu, diperoleh hasil tegangan keluaran sensor yang berbeda-beda dari sensor 1 sampai sensor 8. Hal ini disebabkan karena dipengaruhi oleh kondisi permukaan lantai yang berdebu, permukaan sensor photodioda yang kotor, dan posisi sensor yang jauh dari permukaan sehingga memiliki kemungkinan tidak pada kondisi ideal. Jadi, pada posisi jarak yang efektif untuk sensor yaitu pada jarak tidak terlalu jauh dari permukaan. Sehingga kami memilih jarak sensor dari permukaan yaitu $0,5 \mathrm{~cm}$.

Adapun rangkaian driver sensor yang akan dihubungkan ke sensor yaitu dimana rangkaian driver sensor ini terdapat IC LM339 serta trimpot $10 \mathrm{~K}$ yang digunakan sebagai rangkaian pembanding keluaran sensor dengan suatu tegangan threshold yang dapat diatur dengan memutar trimpot. Kemudian terdapat pula LED pada output berguna sebagai indikator logika output sehinggakerja sensor mudahdiamati. Dan rangkaian ini juga berfungsi untuk menghubungkan ke mikrokontroler.

Rangkaian driver sensor yang kami gunakan dapat dilihat pada gambar 4 dibawah ini.

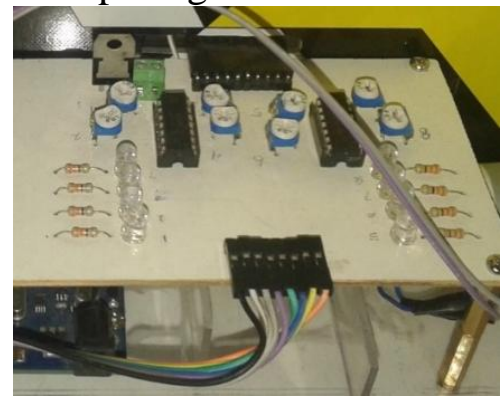

Gambar 4. Rangkaian Driver Sensor

Rangkaian driver sensor yang digunakan merupakan rangkaian inverting dimana ketika diberi inputan $5 \mathrm{~V}$ maka mengeluarkan output 0V. Sebaliknya jika diberi inputan $0 \mathrm{~V}$ maka outputnya adalah 5 V. Tabel 2 berikut merupakan hasil pengujian output sensor.

Tabel 2. Pengujian Output Sensor Pada Garis Hitam.

\begin{tabular}{|c|c|}
\hline KONDISI SENSOR & $\begin{array}{c}\text { OUTPUT } \\
\text { KOMPARATOR } \\
\text { (DALAM BINER) }\end{array}$ \\
\hline & 11111110 \\
\hline & 11111100 \\
\hline & 11111001 \\
\hline & 11111011 \\
\hline & 11110011 \\
\hline & 11110111 \\
\hline & 11100111 \\
\hline & 11101111 \\
\hline & 11001111 \\
\hline & 11011111 \\
\hline & 10011111 \\
\hline & 01111111 \\
\hline
\end{tabular}

Sedangkan hasil pengujian diatas merupakan kondisi sensor terhadap output komparator yang diubah dalam bentuk biner. Dimana sensor yang membaca garis hitam akan bernilai 0 sedangkan sensor yang membaca permukaan putih maka akan bernilai 1 .

Penggunaan 8 buah sensor bertujuan untuk memperoleh hasil pembacaan jalur kerja robot lebih presisi, apabila penggunaan sensor dikurangi menjadi 3 buah sensor maka respon terhadap pembacaan jalur kerja robot akan lambat. Hal ini juga sangat 
mempengaruhi kondisi robot saat berbelok, robot akan cenderung keluar jalur karena kesulitan dalam mendeteksi keberadaan jalur.

Adapun tegangan keluaran

komparator dapat dilihat pada Tabel 3 berikut ini:

Tabel 3.Tegangan keluaran komparator

\begin{tabular}{|c|c|c|}
\hline \multirow{2}{*}{ SENSOR } & \multicolumn{2}{|c|}{$\begin{array}{l}\text { TEGANGAN KELUARAN } \\
\text { KOMPARATOR }\end{array}$} \\
\hline & Putih (V) & Hitam (V) \\
\hline S1 & 5,3 & 0,7 \\
\hline $\mathrm{S} 2$ & 4,6 & 0,7 \\
\hline S3 & 4 & 0,6 \\
\hline S4 & 3,9 & 0,6 \\
\hline S5 & 3,9 & 0,6 \\
\hline S6 & 3,8 & 0,6 \\
\hline S7 & 4,2 & 0,7 \\
\hline S8 & 4 & 0,6 \\
\hline
\end{tabular}

Berdasarkan tabel diatas tegangan keluaran komparator dimana data diatas menunjukkan sensor yang mendeteksi garis hitam akan memiliki tegangan keluaran komparator yang sangat kecil yaitu dibawah $1 \mathrm{~V}$, sedangkan sensor yang tdk mendeteksi garis hitam atau hanya mendeteksi lantai yang berwarna putih akan memiliki tegangan keluaran komparator sebesar diatas $3 \mathrm{~V}$.

\subsection{Rangkaian Driver Motor}

Rangkaian driver motor berfungsi sebagai aktivasi penggerak motor dengan IC L298 yang akan dihubungkan ke arduino. Berikut ini merupakan rangkaian driver motor yang dihubungkan dengan motor DC.

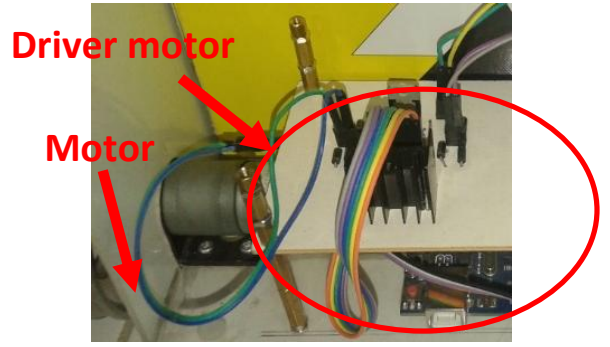

Gambar 5. Rangkaian Driver Motor
Pengujian motor menggunakan driver motor dengan IC L298 dapat dilihat pada Tabel 4 dibawah ini:

Tabel 4. Pengujian Driver Motor DC

\begin{tabular}{cccccccc}
\hline & \multicolumn{2}{c}{ INPUT } & \multicolumn{2}{c}{ ENABLE } & \multicolumn{2}{c}{$\begin{array}{c}\text { OUTPUT } \\
\text { MOTOR }\end{array}$} \\
\hline IN1 & IN2 & IN3 & IN4 & EN1 & EN2 & M1 & M2 \\
\hline $5 \mathrm{~V}$ & $0 \mathrm{~V}$ & $5 \mathrm{~V}$ & $0 \mathrm{~V}$ & $5 \mathrm{~V}$ & $5 \mathrm{~V}$ & $\mathrm{CW}$ & $\mathrm{CW}$ \\
$5 \mathrm{~V}$ & $0 \mathrm{~V}$ & $0 \mathrm{~V}$ & $5 \mathrm{~V}$ & $5 \mathrm{~V}$ & $5 \mathrm{~V}$ & $\mathrm{CW}$ & $\mathrm{CCW}$ \\
$0 \mathrm{~V}$ & $5 \mathrm{~V}$ & $0 \mathrm{~V}$ & $5 \mathrm{~V}$ & $5 \mathrm{~V}$ & $5 \mathrm{~V}$ & $\mathrm{CCW}$ & $\mathrm{CCW}$ \\
$0 \mathrm{~V}$ & $5 \mathrm{~V}$ & $5 \mathrm{~V}$ & $0 \mathrm{~V}$ & $5 \mathrm{~V}$ & $5 \mathrm{~V}$ & $\mathrm{CCW}$ & $\mathrm{CW}$ \\
\hline
\end{tabular}

Berdasarkan tabel tersebut diperoleh hasil pengukuran bahwa output motor 1 bergerak searah jarum jam yaitu $\mathrm{CW}$ (Clock Wise) dimana input 1 dengan tegangan $5 \mathrm{~V}$ dan input 2 dengan tegangan 0V. Sedangkan output motor 2 bergerak berlawanan arah jarum jam yaitu CCW (Counter Clock Wise) ketika input 3 diberi tegangan $0 \mathrm{~V}$ dan input 4 diberikan tegangan $5 \mathrm{~V}$.

Inputan motor (IN1, IN2, IN3, dan IN4) berfungsi untuk penentuan arah putaran motor yaitu $\mathrm{CW}$ atau CCW. Sedangkan pin Enable berfungsi sebagai pengatur kecepatan motor dengan menggunakan teknik PWM (Pulse width Modulation).

PWM yang digunakan disini menggunakan lebar 8 bit sehingga kita bisa memasukkan nilai PWM dari 0 sampai 255 desimal. Nilai tersebut akan dimasukkan melalui pin Enable driver motor DC. Untuk melihat grafik kecepatan PWM dapat menggunakan osiloskop yang kemudian menghubungkan pin-pin enable ke osiloskop.

Tabel 5.Hubungan PWM dengan nilai tegangan DC

\begin{tabular}{ccccc}
\hline \multicolumn{3}{c}{ Osiloskop Digital } & \multicolumn{2}{c}{ Osiloskop Simulasi } \\
PW & Duty & $V_{\text {rata-rata }}$ & $\begin{array}{c}\text { Duty } \\
\text { Cycle }\end{array}$ & $\begin{array}{c}V_{\text {rata-rata }} \\
\left(V_{\text {out }}\right)\end{array}$ \\
M & Cycle & $\left(V_{\text {out }}\right)$ & & \\
& \multicolumn{3}{c}{$37,5 \%$} & $1,875 \mathrm{~V}$ \\
100 & $39,23 \%$ & $1,875 \mathrm{~V}$ & $37,5 \%$ & $3 \mathrm{~V}$ \\
150 & $58,90 \%$ & $3 \mathrm{~V}$ & $60 \%$ & $3,75 \mathrm{~V}$ \\
200 & $78,40 \%$ & $3,75 \mathrm{~V}$ & $75 \%$ & $4,93 \mathrm{~V}$ \\
250 & $98,75 \%$ & $4,93 \mathrm{~V}$ & $98,75 \%$ & \\
\hline
\end{tabular}


Berdasarkan tabel 5 diatas hubungan PWM dengaan nilai tegangan DC yaitu semakin besar nilai PWM maka semakin besar pula nilai tegangan rata-rata pada motor. Hal ini diperoleh dari hasil perhitungan dimana duty cycle dikali dengan tegangan masukan pada motor.

\subsection{Robot PembersihLantai}

Pada rangkaian robot pembersih lantai yakni terdapat rangkaian driver sensor, driver motor, dan sebuah arduino sebagai mikrokontroler pada robot.selain itu, terdapat pula 2 buah motor DC sebagai penggerak roda dan sebuah saklar untuk mengaktifkan robot mmulai bekerja. Berikut ini merupakan gambar rangkaian robot pembersih lantai.

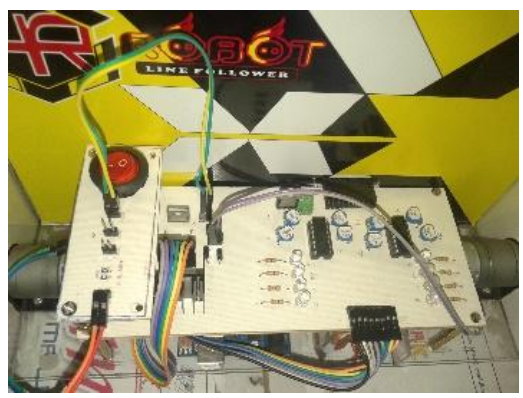

Gambar 6. Rangkaian Robot Pembersih Lantai.

Rancang bangun robot pembersih lantai berbasis arduino dapat dilihat pada gambar dibawah ini.

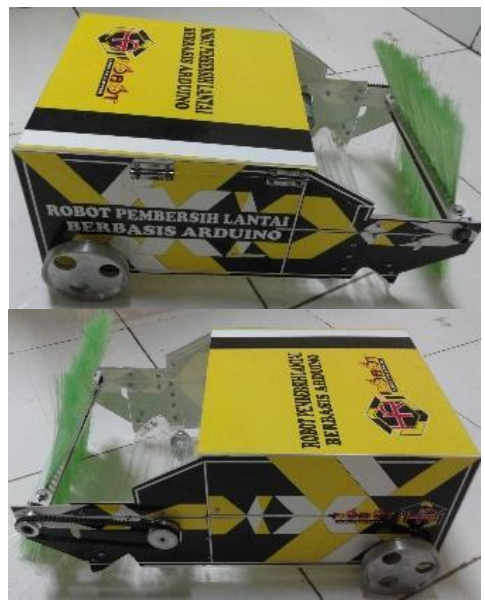

Gambar 7. Rancangan Hasil Karya Robot Pembersih lantai Berbasis Arduino Tampak Samping.

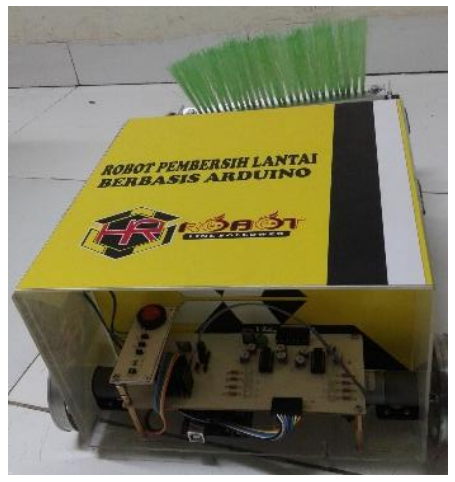

Gambar 8. Rancangan Hasil Karya Robot Pembersih lantai Berbasis Arduino Tampak Belakang.

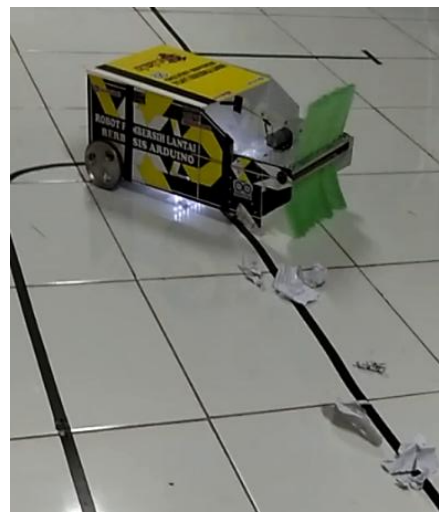

Gambar 9. Robot membersihkan lantai dengan lintasan.

Pengujian robot secara keseluruhan dilakukan dengan cara meletakkan robot di lintasan area pembersihannya. Kemudian menekan saklar untuk mengaktifkan robot sehingga mulai bekerja. Terlihat ketika saklar ditekan maka sapu pembersihannya mulai berputar untuk membersihkan. Bersamaan dengan itu, sensor akan membaca garis dan mulai bergerak membersihkan lantai mengikuti lintasan (garis hitam). Robot pembersih lantai berbasisi arduino ini menggunakan Baterai Lipo dengan tegangan $11,1 \mathrm{~V}$ dan $1000 \mathrm{mAH}$. Sedangkan konsumsi arus pada robot sebesar 0,24 A tanpa beban yaitu pengukuran arus dilakukan dengan cara roda pada robot tidak menyentuh lantai akan 
tetapi semua rangkaian elektronika robot aktif dan tersuplai serta pembersihan robot juga dalam keadaan berputar. Maka untuk mengetahui lama baterai yang di gunakan robot dapat dilihat pada perhitungan dibawah ini:

Diketahui : Arus baterai $=1000 \mathrm{mAH}=1 \mathrm{AH}=\frac{1 \mathrm{~A}}{\mathrm{Jam}}$

Konsumsi arus robot $=0,24 \mathrm{AH}$

$T=\frac{1 A H}{0,24 A H}=4,16 \mathrm{jam}$

Jadi, lama waktu maksimal yang digunakan robot dalam penggunaan baterai Lipo 11,1V dengan arus $1000 \mathrm{mAH}$ adalah sebesar 4,16 jam.

\section{Kesimpulan}

Berdasarkan hasil pengujian yang telah dilakukan dan pengetesan alat maka dapat disimpulkan bahw robot pembersih lantai berbasis arduino merupakan robot yang dapat membersihkan lantai secara efisien dan memudahkan pekerjaan manusia. Dan unjuk kerja robot pembersih lantai berbasis arduino ini bekerja mengikuti garis hitam sebagai jalur kerja robot, robot akan bekerja menggunakan sapu dibagian depan robot untuk membersihkan dan mengangkut sampah kering yang dilaluinya. Robot mampu beroperasi maksimal selama 4,16 Jam dengan kapasitas batterai sebesar 11,1V 1000 mAH secara terus-menerus dan kapasitas pengangkutan sampah sebesar $7.500 \mathrm{~cm}^{3}$.

\section{Saran}

Berdasarkan alat yang telah dibuat yaitu robot pembersih lantai berbasis arduino dengan proses kerja mengikuti garis sebaiknya tidak menggunakan trimpot yang lebih dari $5 \mathrm{KOhm}$ pada rangkaian driver sensor, karena Jika menggunakan trimpot yang lebih dari $5 \mathrm{KOhm}$ sangat sulit mengatur sensitivitas yang sesuai untuk sensor. Pengaturan sensitivitas dilakukan dengan cara memutar trimpot sampai mencapai sensitivitas yang sesuai dengan sensor. Dalam hal ini, pemutaran trimpot yang dilakukan sering sekali terjadi offside sehingga terjadinya kesulitan mencapai sensitivitas sensor yang tepat. Oleh sebab itu, sebaiknya menggunakan trimpot 5 KOhm dan sangat perlu ketelitian dan kesabaran dalam mencari titik sensitivitas sensor yang tepat.

\section{DaftarPustaka}

[1] Eko Prasetyo, "Sistem Gerak Robot Line Follower Menggunakan Motor Dc Berbasis Mikrokontroler Atmega8535 Dengan Sensor Photodioda", Universitas Diponegoro, Semarang, 2010.

[2] Joviana, "Hubungan Konsentrasi Aktivitas”, Universitas Indonesia, Jakarta, 2009.

[3] Tim Dosen Teknik Mekatronika, "Modul Praktek Robotika 1", Politeknik Bosowa, Makassar, 2014.

[4] Tanudjaya Harlia nto, 2011, "Pembersih Lantai", Unika Atma Jaya, Jakarta.https://lib.atmajaya.ac.id/default.as px?tabID=61\&src=k\&id=174693, diakses Selasa, 22 Januari 2016 Pukul 08:37.

[5] Djuandi Feri, 1995, "Pengenalan Arduino", Tenik Elektro Universitas Trisakti, Jakarta. http://tobuku.com/docs/Arduino-

Pengenalan.pdf, diakses Rabu, 20 Juli 2016 Pukul 23:43 WITA.

[6] Ibnu Ziad, "Peralatan Pembersih Lantai Menggunakan Handphone Sebagai Alat Pengontrol", Politeknik Negeri Sriwijaya, Palembang. 2012 